\title{
Exhilarated Learning and the Scholarship of Engagement: From Here (the University) to the Horizon (the Community)
}

\author{
William Ben Strean \\ University of Alberta
}

In this paper, I explain the components of "exhilarated learning," a model for effective classroom environments, and show how this model can be applied to the broader context of communityuniversity engagement. I describe the following three dimensions: human connection, whole body engagement, and linking content to context; and I explore how this model relates to the Scholarship of Teaching and Learning and Scholarship of Engagement.

Wow can the best practices of effective 1 instruction and lessons from the Scholarship of Teaching and Learning (SoTL) inform the Scholarship of Engagement (SoE)? Let us consider three core aspects of optimal classroom learning environments (i.e., human connection, whole body engagement, and consistent linkages between content and context), and explore how they may be extended to developing community-university engagement.

\section{Exhilarated Learning}

While participating in two extensive reflective exercises on best pedagogical practices and innovations, the idea of "exhilarated learning" emerged as an organizing principle that captured the nucleus of three inter-related dimensions.

\section{Human connection: The first dimension}

In virtually any learning environment, students enter with some level of tension, anxiety, and/or resistance. If the stress response is activated, it can decrease the brain's capabilities ability to learn and remember (Kaufeldt, 2010). Nearly all university students have witnessed classrooms in which students are humiliated, put down, or made wrong. At a very basic level, students entering a classroom ask, "Does the professor mean me any harm?" When the instructor creates a welcoming environment and develops positive relationships with students, it puts students more at ease, and facilitates learning. One of the most fundamental principles in effective teaching 
is increasing teacher/student contact and connection (Chickering \& Gamson, 1987; Lowman, 1995).

Largely under-emphasized in traditional teaching skills programs, this dimension acts on the inevitable wall and unwritten contract between teacher and students. On the students' side, it creates comfort and predisposes learners to explore the content and to remain open to the possibility of suggested behavioural or conceptual changes. On the instructor's side, it may enhance the teacher's confidence, awareness, presence, authenticity, and commitment to results. Many classroom practices such as establishing ground rules, using icebreaker activities, and facilitating relationships between and among students can contribute to a sense of human connection and enhance learning.

\section{Whole-body engagement: The second dimension}

University education is often characterized as an experience that occurs above the neck. Stereotypes include passing information from the notes of the professor to the notes of the students, bypassing both of their minds. Most of our understanding of the mind and rationality are based on metaphors that are not supported by cognitive science. Take for example the enduring notion that rational thought is dispassionate. We know this to be false from studies in neuroscience (Damasio, 1994). Those who have lost the capacity to be emotionally engaged in their lives cannot reason appropriately about moral issues. The traditional Western conception of the person with disembodied reason and an objective world must be replaced with the conception of an embodied person. Among the important implications for teaching and learning is the recognition of the centrality of emotion. All learning occurs in a mood and part of fostering student engagement includes attending to and managing the mood of the classroom.

Including emotions, moods, and the importance of the whole body is a completely different paradigm from simple learning styles. Whole-body engagement leverages all the thinking-feeling-acting channels that people use to absorb new information, concepts, and skills. Students become significantly more engaged with the experiential methods encompassed in this dimension. This may promote faster transfer of knowledge and skills, and higher retention rates (e.g., Barnes, 2005). This dimension goes beyond adding to the typical information dissemination mode; it re-conceptualizes the learner and the learning process.

\section{Content to context: The third dimension}

One of the biggest challenges for instructors is to keep the parts connected to the whole. This component is all about the importance of a big picture focus. Particularly in the delivery of a semester-long course, it is increasingly challenging and important to connect the pieces to the larger pie. Much of education, training, and courseware design historically has been linear and reductionist, which often leaves learners lost and with no overarching vision of the learning objective or purpose of segmented activities. This dimension brings in one of the most essential, but often forgotten, elements of successful education. Learners need to have the parts connected to the whole (Meron \& Peled, 2004). Teachers must be mindful of learners' developing schemata, and draw connections among new information and concepts and prior knowledge (e.g., Zheng, Yang, Garcia, \& McCadden, 2008). Building the connections between content and its broader context provides scaffolding for incorporating new information, facilitates a learner's ability to decide where to pay close attention, helps make inferences, provides a guide to search for memory, aids in editing and summarizing, and helps produce hypotheses about information that is missing (cf., Anderson \& Pichert, 1978).

Teachers facilitate learning by offering practical strategies for students to develop schemata when reading, listening to a lecture, or otherwise being exposed to new ideas so that they are able to recognize familiar ideas and make connections to the text or new ideas. With enough practice, modeling, and exposure, teachers can implement some of these strategies in their classrooms to accommodate students (Navarro, 2008). Awareness of the constant interplay between specific content and the larger context provides students with both the why and the how that contributes to deeper, more meaningful learning and greater satisfaction. 


\section{From SoTL to SoE?}

How might these three dimensions that can assist pedagogical enhancement be taken to a broader framework? In our effort to expand our reach, perhaps there is a useful connection between the Scholarship of Teaching and Learning (SoTL) and the Scholarship of Engagement (SoE). In SoTL, we are interested in good teaching, which is, as Parker Palmer (2007) suggested, akin to weaving a fabric of connectedness between student, teacher, and subject. A fabric of connectedness, then, between community, university, and project/topic may need to be weaved to create good engagement.

SoTL has been conceived as a habit of mind and a set of practices that influence culture in which change occurs and developments can thrive (Hutchings, 2010). At its core, the sine qua non of SoTL is the asking and answering of questions about our students' learning, and sharing our insights. I believe there is a potential pitfall in SoE, much like what I perceive with SoTL, for scholars to pursue academic recognition, while losing connection to practice and application that makes a real difference for real people in the real world. Focusing on human connection, whole-body engagement, and the linking of content to context may help to maintain relationship with these realities.

At the most basic level of the academy, faculty are seeking practical ways to plan, implement, and reflect on engaged scholarship due to productivity expectations (Franz, 2009). As Boyer (1996) noted, an expanded view of scholarship is needed as reward systems frequently do not match academic functions, and professors often find themselves wedged between competing obligations. Yet views may be changing slowly, and reward systems seem to exercise powerful influence. Investment in SoE seems to be correlated with rank and years of service at an institution (Glass, Doberneck, \& Schweitzer, 2011). Participation in SoE continues to appear to be a risk for more junior (especially untenured) faculty members.

The strong benefits of community-university engagement provide great incentive to move forward. Such engagement represents the convergence of the community's interest and the self-interest in the educational institution. The communities that partner with their local colleges and universities surely accrue benefits and there are also benefits to the institution, the students, and the faculty. For example, faculty and students who participate in community service learning are often the biggest advocates for expanding engagement (Beere, Votruba, \& Wells, 2011).

\section{From here to there: Human connection}

Although altering the reward system is definitely a positive step, as Chickering and Gamson (1987) asserted, there "are neither enough carrots nor enough sticks to improve undergraduate education without the commitment and action of students and faculty members. They are the precious resources on whom the improvement of undergraduate education depends" (p. 3). By bonding with the community, that commitment and action may be catalyzed by the deep desire to connect with and to assist other people. At a very basic human level, we all want to help each other. That impulse may be so strong that we have to misrepresent reality when we deny it. As described in Leadership and Self-Deception (Arbinger Institute, 2010), an act contrary to what one feels one should do for another is an act of "self-betrayal." This leads to seeing the world in a way that justifies selfbetrayal, a distorted reality. This process can unravel into mutual mistreatment and collusion in giving each other reason to maintain our justifications. When universities and communities engage in collaborative and caring ways, we may transcend our selfish concerns with rewards and work for something larger and more important. We may, in the words of George Bernard Shaw (1903), then experience "the true joy of life, the being used up for a purpose recognized by yourself as a mighty one." Perhaps just as it may be the foundation of the classroom, human connection may be one of the essential principles in community-university engagement.

\section{From here to there: Whole-body engagement}

It really shouldn't have to be said at this point that we are far more than rational information processors. Yet many seem to cling to trying to persuade behaviour change via data-based argument. It is like trying to 
get an unwilling, unmotivated elephant to change direction through conversation with its rider. Just as the classroom becomes more alive and learning becomes more effective when the emotional and physical are included with the intellectual, wholebody engagement may be another vital notion in university-community collaboration. In this dimension, we go beyond interacting at the level of ideas and concepts; we bring our emotions and physical selves along with our intellects to forge deep and meaningful ties. Successful engagement depends on alignment of the university and community at many levels. Alignment is far more than agreeing on ideas;it includes compatible values, which are emotional and visceral. Understanding and operating from a whole-body perspective is crucial for successful engagement.

\section{From here to there: Content to context}

On the smaller scale of individual learning, we saw how important schema theory can be in helping teachers to facilitate learners linking specific content with a larger representation. Such an approach can be invaluable in helping to link communities and universities with their often-disparate points of view. Greeno and van de Sande (2007) developed an extension of the theory of conceptual understanding in interaction, emphasizing the importance of alignment between perspectives of participants. They consider the theory of perspectival understanding as a generalization of schema theory. A crucial factor in developing engagement may be acknowledging how various points of view or beliefs are not isolated, but rather fit within a larger scheme and can be aligned. Just as connecting bits of information to broader concepts can foster individual understanding, making associations among perspectives can cultivate understanding between communities and universities.

\section{Conclusion and Future Directions}

Whether trying to navigate the complexity of the classroom or attempting to develop valuable engagement between the community and the university, three core dimensions may ease the process: human connection, whole-body engagement, and linking content to context. Whereas there appears to be good evidence for instructional application, the difficulty may be to implement these useful ideas more fully in the increasingly important area of communityuniversity engagement. Engaged scholars will have to overcome the conundrums of university reward structures (Nicotera, Cutforth, Fretz, \& Thompson, 2011) and find creative approaches to pursue sustainable engagement (Shea, 2011). Successful navigation of these challenges will result in personally and professionally meaningful contributions from here to the horizon.

\section{References}

Anderson, R.C. \& Pichert, J.W. (1978). Recall of previously unrecallable information following a shift in perspective. Journal of Verbal Learning and Verbal Behavior, 17, $1-12$.

Arbinger Institute. (2010). Leadership and selfdeception (2nd ed.). San Francisco: BerrettKoehler.

Barnes, J. (2005). "You could see it on their faces..." The importance of provoking smiles in schools. Health Education, 105(5), 392-400.

Beere, C.A., Votruba, J.C., \& Wells, G.W. (2011). Becoming an engaged campus: A practical guide for institutionalizing public engagement. San Francisco: Jossey-Bass.

Boyer, E.L. (1996).The scholarship of engagement. Journal of Public Service\& Outreach, 1(1), 11-20.

Chickering, A.W. \& Gamson, Z.F. (1987). Seven principles for good practice in undergraduate education. AAHE Bulletin, 3-7. 
Damasio, A.R. (1994). Descartes' error: Emotion, reason and the human brain. New York: Grosset/Putnam.

Franz, N. (2009). A holistic model of engaged scholarship: Telling the story across higher education's missions. Journal of Higher Education Outreach and Engagement, 13(4), $31-50$.

Glass, C.R., Doberneck, D.M. \& Schweitzer, J.H. (2011). Unpacking faculty engagement: The types of activities faculty members report as publicly engaged scholarship during promotion and tenure. Journal of Higher Education Outreach and Engagement, 15(1),730.

Greeno, J.G. \& van de Sande, C. (2007). Perspectival understanding of conceptions and conceptual growth in interaction. Educational Psychologist, 42(1), 9-23.

Hutchings, P. (2010). The scholarship of teaching and learning: From idea to integration. New Directions for Teaching and Learning, 63-72.

Kaufeldt, M. (2010). Begin with the brain: Orchestrating the learner-centered classroom. Thousand Oaks, CA: Corwin.

Lowman, J. (1995). Mastering the techniques of teaching (2nd ed.). San Francisco: JosseyBass.

Meron, R. \& Peled, I. (2004). Situated or abstract: The effect of combining context and structure in constructing an additive schema. Bergen, Norway: International Group for the Psychology of Mathematics Education.

Navarro, A. (2008). Building schema for English language learners. (ERIC Document Reproduction Service No. ED514335). Retrieved August 18, 2011 from EBSCOHost ERIC database.
Nicotera, N., Cutforth, N., Fretz, E., \& Thompson, S.S. (2011). Dedication to community engagement: A higher education conundrum? Journal of Community Engagement and Scholarship, 4(1), 37-49.

Palmer, P. (2007). The courage to teach: Exploring the inner landscape of the teacher's life (10th anniversary ed.). San Francisco: Jossey-Bass.

Shaw, G.B. (1903). Man and superman. Cambridge, MA: The University Press.

Shea, J. (2011). Sustainable engagement? Reflections on the development of a creative communityuniversity partnership. Gateways: International Journal of Community Research, 4, 136-153.

Zheng, R.Z., Yang, W., Garcia, D., \& McCadden, E.P. (2008). Effects of multimedia and schema induced analogical reasoning on science learning. Journal of Computer Assisted Learning, 24,474-482.

\section{Biography}

Billy Strean is Professor in the Faculty of Physical Education and Recreation at the University of Alberta and a 2011 recipient of the 3M National Teaching Fellowship. 